\title{
Financiamento popular. a percepção do processo e de suas consequências nas classes menos favorecidas
}

\section{Popular financing: how the process and its consequences are perceived by lower classes}

\author{
${ }^{1}$ Greyce Kelly Macêdo da Costa \\ ${ }^{2}$ Irene Raguenet Troccoli
}

1 B. Sc. em Administração de Empresas, Universidade Estácio de Sá.

2 D. Sc. em Administração de Empresas, Universidade Estácio de Sá.

\section{RESUMO}

Qual a visão dos representantes das classes C e D/E, ao se tornarem tomadores das linhas de crédito e de financiamentos incentivados pelo Governo Federal, quanto às condições processuais dessa tomada, $\mathrm{e}$ quais os reflexos que essa tomada possa ter sobre a organização financeira dessas pessoas? Essas são as questões que esta pesquisa, utilizando a técnica de análise de discurso, busca responder, ainda que de forma parcial. A conclusão é de que essa visão pode variar desde a interpretação de que se trata de processo complexo até um evento não só simples como rápido, dependendo dos próprios perfis dos usuários. Também ficou indicado que, de uma forma geral, os sujeitos pesquisados não deixaram que essa tomada de crédito impactasse negativamente em suas finanças pessoais.

\section{PALAVRAS-CHAVE:}

Classes C e D/E; crédito popular; finanças pessoais.

\section{ABSTRACT}

What is the opinion of classes $C$ and $D / E$ representatives, when borrowing official credit about the technical procedures, and what consequences does this borrowing have on their personal finances? This qualitative research searches to answer these questions using discourse analysis. The conclusion is that this event may be complicated or not, depending on the user's profiles, and, in a general way, the subjects did not let this operation impact negatively their personal finances.

\section{KEYWORDS:}

Classes $C$ and D/E; popular credit; personal finances.

\section{Como você deve citar?}

COSTA, G. K. M.; TROCCOLI, I. R. Financiamento popular: um primeiro passo na percepção do processo e de suas consequências nas classes de baixa renda. Cadernos UniFOA, Volta Redonda, n 25 , quadrimestral, p. 53-68, ago. 2014. 


\section{INTRODUÇÃO}

A partir de meados do primeiro decêndio dos anos 2000, o Brasil passou a experimentar diversas mudanças socioeconômicas originadas de iniciativas de programas federais de transferência de renda, que buscavam uma melhoria no poder de compra das classes de baixa renda. Queiroz et al (2010) citam alguns, característicos de transferência direta de renda: Bolsa-Escola, Bolsa-Alimentação, Auxílio-Gás, Cartão Alimentação, Programa Fome Zero e Bolsa Família.

Como resultados desses esforços, o poder de compra da população brasileira ascendeu fortemente:

\footnotetext{
Duas pesquisas divulgadas nesta segunda-feira, (dia) 8 (de agosto de 2011) tecem o panorama da Classe C, a chamada nova classe média, que já é a maior camada da população no Brasil. O levantamento divulgado pelo Data Popular mostra que a classe média cresceu $12 \%$ nos últimos sete anos: em 2003 , equivalia a $40 \%$ da população. Atualmente este índice é de $52 \%$. Essa é a primeira vez em que a classe $C$ configura mais da metade da dos habitantes do país. O percentual representa 31 milhões de pessoas que ingressaram na classe média na última década, o que faz subir para 95 milhões o número de brasileiros nessa faixa social. (THOMAZ, 2011, sem página definida)
}

Em paralelo, o mesmo governo federal lançou, no ano de 2007, o Programa de Aceleração do Crescimento (PAC), conjunto de políticas econômicas planejadas para os quatro anos seguintes com investimentos fundamentalmente em infraestrutura - saneamento, habitação, transporte, energia e recursos hídricos, entre outros (PAC, 2013). No bojo desse programa inseriram-se iniciativas específicas para favorecer o consumo das classes de baixa renda, tais como os programas Minha Casa, Minha Vida e o financiamento habitacional que utiliza recursos do Sistema Brasileiro de Poupança e Empréstimo (SBPE) (CAIXA, 2013). E, mais recentemente, a diversidade de iniciativas aumentou; exemplo foi a disponibilização da linha de crédito Minha Casa Melhor, financiamento para móveis populares e eletrodomésticos para os beneficiários do programa Minha Casa, Minha Vida.

Essas iniciativas, portanto, visavam a que, uma vez satisfeitas as necessidades mais básicas da população em geral, os esforços passassem a ser direcionados para o atendimento de urgências de consumo mais imediato das famílias de classes de baixa renda, a serem atendidas por meio da concessão de linhas de crédito.

Tendo em vista esses elementos, este artigo teve dois objetivos. 0 primeiro foi dar um primeiro passo na investigação sobre a visão dos representantes das classes $\mathrm{C}$ e $\mathrm{D} / \mathrm{E}$, ao se tornarem tomadores das linhas de crédito e de financiamentos incentivados pelo Governo Federal, quanto às condições processuais dessa tomada. 0 segundo objetivo foi, também de forma parcial, investigar os reflexos que essa tomada possa ter sobre a organização financeira dessas pessoas.

Para tanto, ele está estruturado em quatro partes, além desta introdução: o referencial teórico, a apresentação da metodologia, os resultados da pesquisa de campo primária e as conclusões.

\section{REFERENCIAL TEÓRICO}

\subsection{Consumidor de baixa renda}

Uma das medidas mais conhecidas no Brasil para classificar a população em termos socioeconômicos é aquela disponibilizada pela Associação Brasileira de Empresas de Pesquisa (Abep), denominada Critério de Classificação Econômica Brasil (CCEB) (ABEP, 2013). Sua construção se dá 
a partir de levantamento de duas características domiciliares: presença e quantidade de alguns itens domiciliares de conforto, e grau escolaridade do chefe de família.

No primeiro caso, são analisadas as quantidades de bens e de serviços presentes nos domicílios: televisões em cores, rádio, banheiro, automóvel, empregada mensalista, máquina de lavar, videocassete e/ou DVD, geladeira e freezer. Já no que tange ao grau de instrução do chefe de família, este é enquadrado em um de cinco níveis (a Abep não informa o que significam os níveis 1 e 2 de escolaridade): 1) analfabeto ou com ensino fundamental 1 incompleto; 2) com ensino fundamental 1 completo ou com ensino

fundamental 2 incompleto; 3) com ensino fundamental 2 completo ou com ensino médio incompleto; 4) com ensino médio completo ou com ensino superior incompleto; e 5) com ensino superior completo.

Com isso, são constituídos oito níveis de cada classe econômica - A1, A2, B1, B2, C1, C2, D, E cujas respectivas rendas médias brutas mensais familiares, no início de 2013, encontram-se na Tabela 1.

Tabela 1 - Critério de Classificação Econômica Brasil - Classes e renda média bruta familiar em 2013.

\begin{tabular}{l|l}
\hline Classes de renda & Renda média bruta familiar mensal (R\$) \\
\hline A & $9.263,00$ \\
\hline \multicolumn{2}{|l}{} \\
\hline B1 & $5.241,00$ \\
\hline B2 & $2.654,00$ \\
\hline C1 & $1.685,00$ \\
\hline D2 & $1.147,00$ \\
\hline
\end{tabular}

Fonte: (ABEP, 2013)

Com a atual política econômica expansionista brasileira (WILHER, 2013), a população de baixa renda tem contribuído com o consumo, com especial relevância para os jovens entre 20 e 30 anos de idade que adentraram o mercado formal de trabalho. Assim, ao mesmo tempo em que esses consumidores passaram a almejar mais crédito em função do aumento da sua renda, a inadimplência passou a apresentar recuos mensais no ano de 2013 (ESTADÃO, 2013).

No bojo dessa configuração cresceu o número de consumidores considerados de alto risco em busca de cartões de crédito, instrumento visto como forma rápida de propiciar o acesso aos bens de consumo almejados.

A classe E vem aumentando sua participação no mercado de cartões de crédito. Se em 2009 os consumidores com renda mensal média de até um salário mínimo ( $\mathrm{R} \$ 678$, hoje) representavam $6,2 \%$ da demanda por cartões, em 2013 o número passou para 16,8\%, de acordo com estudo divulgado nessa quarta-feira (4) pela Serasa Experian. (FOLHA DE SÃO PAULO, 2013, sem página definida)

Esse movimento serviu de combustível para a previsão de que o consumo das famílias brasileiras, em 2013, apresente aumento de $10 \%$ comparativamente ao observado no ano anterior $(\mathrm{G} 1,2013)$, perspectiva que tem sido alimentada pelo ritmo de consumo de uma parcela, em especial, da população: a chamada nova classe C. De acordo com a Secretaria de Assuntos Estratégicos (SAE) da Presidência da República, trata-se das famílias com renda per capita mensal entre $\mathrm{R} \$ 291,00$ e $\mathrm{R} \$ 1.019,00$, que foi 
formada a partir das políticas de melhorias do poder de compra promovidas no País a partir de 2003, com destaque para a geração de empregos formais, para a recuperação do salário mínimo em termos reais e para a inclusão socioeducativa.

Por seu turno, esse fenômeno do aumento da importância da população de baixa renda na contribuição do crescimento da economia brasileira através do consumo passou a contar com combustível extra, conforme o governo federal passou a se preocupar em propiciar-Ihe maior facilidade de acesso a programas de crédito.

\subsection{Linhas de crédito e de financiamento para a população de baixa renda}

Segundo Morcillo (2007, p.134), os motivos pelos quais a população brasileira recorre a empréstimos via crédito e financiamentos estão ligados a fatores aleatórios e transitórios, ou seja, quando o indivíduo passa transitoriamente por redução da renda e deseja manter seus planos de compra de bens e de serviços conforme sua renda média: "Os intermediários financeiros transferem fundos de quem concede empréstimos para aqueles que tomam empréstimos e, dessa forma, criam ativos financeiros como as contas correntes (depósitos à vista), ou seja, a moeda bancária."

Esses produtos financeiros, por sua vez, vêm sofrendo aumento tanto de quantidade quanto de diversidade para população de renda mais baixa. Um dos alavancadores desse movimento tem sido o Programa de Inclusão Bancária, ação conjunta do Ministério do Desenvolvimento Social e da Caixa Econômica Federal (CEF) para incentivar a inserção dos beneficiários do Programa Bolsa Família (PBF) no Sistema Financeiro Nacional, a partir da abertura e utilização de contas bancárias simplificadas. Criado em 2003, dois anos após ele já era responsável por mais de 3,8 milhões de brasileiros com renda mensal de até $R \$ 1.000$ terem passado a ter acesso a serviços bancários e a crédito no Banco do Brasil e na CEF (FOLHA ONLINE, 2005). Atualmente, o destaque desses produtos financeiros para as classes economicamente mais baixas, cuja lista segue abaixo, fica por conta de seis deles: Caixa Econômica Federal, Banco Itaú, Banco Bradesco e Banco do Brasil:

1. Crédito Pessoal: trata-se de um empréstimo com um limite pré-aprovado, em que o cliente correntista pode obter sem necessidade de comprovação de sua finalidade, sendo que as condições da contratação variam de acordo com a instituição financeira escolhida (CRÉDITO PESSOAL, 2014).

2. Microcrédito: é oferecido para quem trabalha por conta própria - donos de empreendimentos pequenos com CNPJ - ou para trabalhadores informais, com a finalidade de possibilitar o financiamento de equipamentos, a compra de materiais de construção e a reposição de estoques (MICROCRÉDITO CAIXA, 2014). De acordo com o Sebrae (2013)', o microcrédito raramente financia o consumo, sendo voltado ao financiamento das atividades produtivas dos pequenos empreendedores. Dentre as características, consta que o montante oferecido é sempre compatível com a necessidade do negócio, que as exigências de documentação dependem das normas da instituição cedente, que os prazos de pagamentos são geralmente curtos, e que as garantias exigidas são mais simples, podendo o cliente escolher uma pessoa de seu relacionamento pessoal para ser avalista da operação.

3. Empréstimo consignado: trata-se de empréstimo descontado diretamente ou em folha de pagamento (no caso de trabalhadores com carteira assinada) ou na renda obtida via benefício (no caso de aposentados e pensionistas), podendo também destinar-se a servidores públicos e a funcionários de empresas privadas que possuem convênio com uma instituição financeira. Esse tipo de linha creditícia tem a vantagem de contar com taxa de juros menor que as demais opções de empréstimo, não havendo a necessidade de o tomador informar o que pretende fazer com o montante obtido (EMPRÉSTIMO CONSIGNADO, 2014). 
4. Crédito Direto ao Consumidor (CDC): tem a finalidade de financiar diversos projetos que o tomador venha a negociar diretamente com terceiros. Pode envolver bens duráveis ou de serviços, por exemplo, cirurgia plástica, despesas cartorárias, intercâmbio, adaptação de veículos, aquisição de aparelhos auditivos, material de construção, kit gás, pacote de viagens, cursos, veículos e embarcações (CRÉDITO DIRETO AO CONSUMIDOR, 2014).

5. Cheque Especial: é um limite de crédito disponível em conta corrente para ser utilizado quando do esgotamento do dinheiro do próprio cliente e que, geralmente, é implantado quando da abertura de conta corrente em qualquer banco. Para tanto, é necessário apenas que o cliente assim permita, e que seu nome não esteja vinculado a nenhuma restrição financeira (CHEQUE ESPECIAL, 2014).

6. Crédito Imobiliário: pode ser usado em conjunto com os recursos do Fundo de Garantia do Tempo de Serviço do trabalho (FGTS). Destina-se ao financiamento da casa própria, existindo também a possibilidade de ser usado para aquisição de lote urbano. Pelas regras, até $80 \%$ do valor pode ser pago com esses recursos e o prazo para ser saldado é de até 30 anos (CRÉDITO IMOBILIÁRIO, 2014).

\subsection{Incentivos do governo federal à tomada de crédito para a população de baixa renda}

Desde o ano de 2003, o governo federal brasileiro tem promovido ações para promover a inclusão da população de baixa renda no consumo da sociedade. Dentre aqueles destinados a moradia, os mais propagados são três:

1. Programa Minha Casa Minha Vida (MINHA CASA, MINHA VIDA, 2014): oferecido por meio da CEF, visa a facilitar a compra da casa própria para as famílias urbanas com renda bruta até $R \$ 1.600,00$ e famílias com renda até $\mathrm{R} \$ 5$ mil, por meio de descontos, de subsídios e da redução do valor de seguros habitacionais. Também contempla famílias que vivem no campo com renda anual até $R \$ 15$ mil, podendo ser operacionalizado em conjunto com o uso dos recursos do FGTS de que o tomador eventualmente disponha. Para se habilitar a esse programa, o primeiro passo é a aprovação do cadastro e do crédito, com a instituição financeira avaliando os chamados cinco " $\mathrm{C}$ " ligados à exigência de crédito, cuja veracidade é de responsabilidade do cliente no repasse à CEF: 1) caráter (intenção de pagar), 2) capacidade (habilidade para pagar), 3) condições (ambiente externo e conjuntural do cliente), 4) colateral (garantias referentes à vinculação de bens patrimoniais das pessoas físicas ou jurídicas), e 5) capital (situação econômico-financeiro do cliente pessoa física, que pode ser expressa por sua declaração do imposto de renda). Em seguida, a CEF analisa também a documentação dos vendedores, assim como os seus engenheiros avaliam o imóvel. Finalmente ocorre a definição da melhor opção de financiamento, com o cliente assinando o contrato e com o vendedor recebendo seu pagamento quando do registro oficial da operação.

2. Programa Nacional de Habitação Rural (PNHR) (PROGRAMA NACIONAL DE HABITAÇÃo RURAL, 2014): destinado aos produtores rurais com renda familiar bruta anual de até $R \$ 60$ mil, tem como objetivo reduzir o déficit habitacional rural. Dentre as exigências destacam-se a de o tomador não ter prévio financiamento imobiliário ativo no Sistema Financiamento Habitacional (SFH), não ter restrições junto à Receita Federal, não ser proprietário nem cessionário nem promitente comprador de imóvel residencial em qualquer localidade do território brasileiro e não ser nem ter sido beneficiário de programas habitacionais.

3. Programa Crédito Solidário (PCS) (PROGRAMA CRÉDITO SOLIDÁRIO, 2014): oferecido através da CEF, visa a ajudar famílias com renda bruta mensal entre $R \$ 1.125,00$ e $R \$ 1.900,00$ a comprar ou a reformar suas habitações. Para tanto, são utilizados recursos do Fundo de Desenvolvimento Social (FDS), destinado ao financiamento de projetos de investimentos nas áreas de habitação popular, de 
saneamento básico, de infraestrutura urbana e de equipamentos comunitários. O PCS pode ser usado para aquisição de terrenos destinados à construção de imóveis em terreno próprio ou de terceiros, ou para o acabamento de imóveis.

Mais recentemente, em junho de 2013 , o governo federal anunciou mais um estímulo ao consumo das famílias de renda mais baixa, destinado à compra de móveis, de eletrodomésticos e de computadores por parte do público beneficiado pelo programa habitacional Minha Casa, Minha Vida (VILLAVERDE, 2013). No caso, os mutuários do programa passaram a receber cartão magnético da CEF com limite de R 5 mil para serem gastos na compra desses itens, com taxas de juros fixas de $5 \%$ ao ano e com prazo de pagamento de até 48 meses.

Em paralelo a essas iniciativas, o governo federal brasileiro tem buscado alavancar o consumo das famílias com menor poder aquisitivo, ao promover a diminuição de preço de itens de uso doméstico através de redução tributária.

A eliminação temporária total ou parcial da alíquota do Imposto sobre os Produtos Industrializados (IPI) foi aplicada a itens da linha branca, a partir de dezembro de 2011: para fogão passou de 4\% para zero; para geladeira, de $15 \%$ para $5 \%$; para máquina de lavar, de $20 \%$ para $10 \%$; e para máquina de lavar semiautomática ("tanquinho"), de 10\% para zero (PORTAL BRASIL, 2012). 0 segmento de móveis também foi beneficiado, no fim de 2009, e seu IPI foi zerado, também temporariamente,

Esse movimento reforçou-se em maio de 2012, com sua extensão ao segmento de veículos novos, o que lhes acarretou o barateamento nos preços em até $10 \%$ (BALDOCHI, 2012). Embora o governo tenha informado que a medida não foi suficiente para trazer o fôlego desejado à fabricação de automóveis no País, ela não deixou de reanimar essa indústria e de incentivar famílias de classes menos abastadas a adquirir um veículo novo ou seminovo. Conforme Felix (2012, sem página definida).

A redução do IPI de automóveis aumentou ainda mais a participação dos carros como meio de transporte preferido dos brasileiros para viagens em 2012. Pesquisa da Fecomércio - RJ / Ipsos revela que o percentual de brasileiros que viajou ou tem intenção de viajar em 2012 é de $29 \%$ (em2011 eram $32 \%$. Na classe C, entre os $25 \%$ com intenção de viajar, a opção por carros subiu de $19 \%$ para $26 \%$ e a de avião, de $9 \%$ para $14 \%$.

Outro movimento do Governo federal com a mesma intenção consubstanciou-se no Construcard, linha de financiamento obtido junto à $C E F$, destinado à compra de material de construção para residências. No caso, o tomador desse empréstimo passa a dispor de prazo de dois a seis meses para adquirir o referido material necessário, período durante o qual paga somente o juros dos valores utilizados; em seguida, dispõe de até oito anos para efetuar o pagamento mensal das prestações do financiamento. (CAIXA ECONOMICA FEDERAL, 2013)

Finalmente, vale mencionar o Programa de Arrendamento Residencial (PAR): promovido pelo Ministério das Cidades, tendo a CAIXA como agente executor e o Fundo de Arrendamento Residencial (FAR) como financiador. $O$ programa visa a ajudar municípios e estados a atenderem à necessidade de moradia da população que recebe até seis salários mínimos e que vive em centros urbanos. 0 programa é desenvolvido em duas fases distintas, sendo a primeira a compra de terreno e a contratação de uma empresa privada do ramo da construção, responsável por construir as unidades habitacionais; estas, uma vez prontas, são arrendadas com opção de compra do imóvel ao final do período contratado (CAIXA ECONÔMICA FEDERAL, 2013). 


\section{METODOLOGIA}

Esta pesquisa qualifica-se como qualitativa pelo ângulo da abordagem, tendo em vista seu foco ter sido aprender e interpretar, com elevado envolvimento da pesquisadora. Já quanto aos meios, qualifica-se como exploratória, já que a pesquisadora não tinha uma ideia clara dos problemas que encontraria ao longo do trabalho; ademais, trata-se de área de investigação relativamente nova, tendo em vista a recenticidade da ascensão econômica da população brasileira de baixa renda (COOPER; SCHINDLER, 2011).

No que diz respeito aos fins, ela se constituiu de pesquisa de campo (VERGARA, 2013). Foram levantadas tanto informações secundárias via busca bibliográfico-documental junto a instituições financeiras e a veículos de divulgação de notícias - jornais, revistas - como informações primárias por meio de entrevistas com os sujeitos selecionados.

O levantamento das informações primárias se deu por meio de entrevistas semiestruturadas realizadas com oito pessoas pertencentes às classes $C$ e $D / E$, de acordo com o CCEB, que haviam recentemente se inserido em algum tipo de programa de financiamento subsidiado pelo governo federal para a parcela da população de baixa renda. Elas foram selecionadas pelo critério de conveniência pela pesquisadora, que as consultou previamente sobre sua aceitação em participar de pesquisa destinada à confecção de artigo acadêmico.

A maior parte das entrevistas foi realizada no local de trabalho da pesquisadora - comum a alguns dos sujeitos selecionados - após o horário de trabalho. A duração média foi de 30 minutos e, inicialmente, foi realizado pré-teste junto com duas dessas pessoas, cujo resultado não foi descartado, já que foi julgado consistente.

As conversas foram gravadas para posterior transcrição, que foi analisada com base em técnica descrita a seguir. Além disso, a pesquisadora anotou os pontos mais relevantes de cada conversa para posterior análise, assim como se esforçou para observar as reações dos entrevistados em termos de gestos, de expressões faciais e de entonações, já que se trata de aspectos que podem agregar entendimento às opiniões formalmente manifestadas.

Durante esses encontros, os entrevistados selecionados puderam expressar o passo a passo da tomada do crédito, a finalidade, como ficou o orçamento familiar após essa ação, quais foram os tipos de crédito ou financiamento realizados, o seu nível de satisfação com a aquisição do bem, qual foi o critério de escolha, se as prestações ficaram acessíveis, se houve divergência de informações no momento da assinatura do contrato, se possuíam outras linhas ativas de financiamento ou de crédito, como administraram as contas de consumo em paralelo às prestações assumidas e se tinham o costume de juntar uma reserva financeira para necessidades inesperadas.

O conteúdo das conversas, auxiliado pela lembrança e pelas anotações da pesquisadora em relação às reações dos entrevistados, foi tratado por meio da técnica da análise de discurso, numa vertente aqui denominada soft, conforme buscou reproduzir os procedimentos adotados por Damascena e Farias $(2013$, p. 7$)$ :

A análise de discurso é a "interpretação fundamentada em uma argumentação detalhada e uma atenção cuidadosa ao material que está sendo estudado" (GILL, 2002, p. 266). A atenção tratada pela autora refere-se à preocupação com os dados coletados e o contexto em que ocorreu a coleta desses dados. Durante a realização das entrevistas, foram observados e anotados no caderno de campo os gestos, entonações da voz, pausas, respirações, aspectos linguísticos e expressões faciais que implicassem em mudanças de sentido, objetivando 


\begin{abstract}
identificar os aspectos não verbais que o pesquisador considerou importantes para a análise do discurso. Assim, foram considerados os aspectos linguísticos, relacionados à forma como algumas palavras e expressões foram utilizadas e aspectos extralinguísticos, que são os gestos, posturas, expressões faciais. Os aspectos linguísticos foram expostos entre parênteses, para: a) evidenciar sujeitos ou objetos ocultos nos trechos destacados; b) explicar expressões linguísticas ou colocações cotidianas e; c) evidenciar o uso de recursos linguísticos, como ironias, por exemplo. Os aspectos extralinguísticos foram expostos entre colchetes, para: a) evidenciar os gestos, posturas, expressões faciais; b) evidenciar pausas e silêncios. As pausas curtas, relativas à respiração ou
\end{abstract}

a pequenos silêncios são inseridas por meio de reticências. Já as pausas longas, consideradas momentos de silêncio, estão identificadas com a palavra "pausa" entre colchetes.

Dentre as limitações mais relevantes sofridas por esta pesquisa podem ser citadas quatro: 1) a autora da pesquisa é colega de trabalho de alguns dos entrevistados, o que pode ter afetado as respostas desses últimos, caso eles tenham, por algum motivo relativo a essa convivência, calibrado suas respostas de forma a construí-las de acordo com aquilo que julgavam que a pesquisadora desejava ouvir; 2) tratando-se de assunto de fundo financeiro, alguns dos entrevistados podem não ter se sentido à vontade para aplicar plena honestidade em suas respostas, filtrando-as conforme suas crenças pessoais; 3) tratando-se de pesquisa de abordagem qualitativa, revelam-se os perigos implicados pela flexibilidade que o pesquisador possui, já que, de acordo com sua visão, podem-se conseguir variadas respostas para um mesmo fenômeno; e 4) também pelo fato de se tratar de pesquisa restrita à abordagem de oito pessoas, os resultados não podem ser considerados genéricos.

Os temas mais relevantes apontados nas entrevistas se encontram no próximo item deste artigo, ilustrados com passagens das conversas consideradas representativas.

\title{
4 RESULTADOS DA PESQUISA DE CAMPO PRIMÁRIA
}

As características pessoais dos oito entrevistados encontram-se no Quadro 1. Observa-se que os sujeitos selecionados foram homens em sua maioria, com idades que variaram entre o mínimo de 23 e o máximo de 40 anos de idade. Três são bancários, dois são vigilantes, um é funcionário público e dois são profissionais liberais. Quanto à renda média mensal, ela variou entre o mínimo de R\$930 e o máximo de R\$ 3 mil, e todos os entrevistados, à exceção de um que adquiriu o Cartão Construcard, tomaram crédito imobiliário. 
Quadro 1 - Características pessoais dos entrevistados.

\begin{tabular}{|l|l|l|l|l|l|}
\hline DENominação & GÊNERO & IDADE & PROFISSÃO/ OCUPAÇÃO & $\begin{array}{l}\text { RENDA MÉDIA } \\
\text { MENSAL }\end{array}$ & $\begin{array}{l}\text { TIPO DE CRÉDITO } \\
\text { TOMADO }\end{array}$ \\
\hline E1 & Feminino & 40 & $\begin{array}{l}\text { Corretora de Seguros de } \\
\text { Vida }\end{array}$ & $R \$ 3.000$ & Crédito Imobiliário \\
\hline E2 & Masculino & 24 & Bancário / Caixa & $R \$ 3.000$ & Crédito Imobiliário \\
\hline E3 & Masculino & 33 & Vigilante & $R \$ 3.000$ & Cartão Construcard \\
\hline E4 & Feminino & 23 & Bancário / Caixa & $R \$ 2.000$ & Crédito Imobiliário \\
\hline E5 & Masculino & 32 & Vigilante & $R \$ 1.200$ & Crédito Imobiliário \\
\hline E6 & Feminino & 25 & $\begin{array}{l}\text { Bancário / Gerente de } \\
\text { Contas }\end{array}$ & $R \$ 3.000$ & Crédito Imobiliário \\
\hline E7 & Masculino & 25 & $\begin{array}{l}\text { Administrador de } \\
\text { Empresas }\end{array}$ & $R \$ 930$ & Crédito Imobiliário \\
\hline E8 & Masculino & 30 & $\begin{array}{l}\text { Servidor Público/ } \\
\text { Operador Triagem e } \\
\text { Transbordo dos Correios }\end{array}$ & $R \$ 1.800$ & Crédito Imobiliário \\
\hline
\end{tabular}

Fonte: Elaboração própria

No que diz respeito às condições para acessar o crédito, no caso do Cartão Construcard, o relato de E3 indicou que não houve maiores dificuldades para adquiri-lo:

\footnotetext{
...foi bem fácil, eu fui lá um dia antes, aí ele (o gerente da CEF) fez uma simulação, perguntou a minha renda, quanto eu ganhava. Este processo todo, né? [pausa] Levei a documentação, ele fez a simulação e aprovou. [expressão de satisfação] (E3) [sic]
}

Já E5, que tomou crédito imobiliário e que tem a mesma profissão de $E 3$, mas renda menor e sem nenhuma poupança prévia - havia "perdido o hábito de guardar dinheiro" - relatou que seu processo foi mais complexo. Inicialmente ele economizou apenas o valor necessário para levantar a documentação exigida para aderir ao PAR e expôs seu entendimento sobre este recurso: "É um acordo entre o governo e a Caixa Econômica pra... No caso, pra beneficiar (o cliente) no financiamento do imóvel. Foi um condomínio feito pela Caixa com a prefeitura, e financiado para os arrendatários." (E5) [sic]

Ele também contou como conseguiu habilitar-se no programa sem dispor de recursos para compor a entrada normalmente exigida nos financiamentos e programas para baixa renda mais conhecidos: "Fazendo pesquisa consegui essa informação, que (eu) tinha que fazer a inscrição na prefeitura e aguardar o sorteio. E eu fui sorteado, no caso... com a aquisição da casa." (E5) [sic]

Os demais entrevistados tomaram crédito imobiliário através do Programa Minha Casa Minha Vida, dentre os quais E1, E6 e E7 já detinham certo conhecimento prévio a respeito do financiamento. Os dois primeiros optaram por contratar despachante para deslanchar o processo, por motivos diferentes. No caso de E1, como já havia anteriormente tomado (pessoalmente) empréstimo junto à CEF, não quis vivenciar o trâmite novamente, por não ter sido uma experiência agradável. Já E2 preferiu contar com essa ajuda por uma questão de falta pessoal de tempo para acompanhar a burocracia.

De qualquer forma, em ambos os casos essa providência contribuiu para azeitar a operação e a evitar gastos desnecessários com documentações ou consequentes à eventual falta de informação, não tendo havido ruídos nas comunicações com o banco e com o processo revelando, inclusive, agilidade: 
É, assim... Até pela primeira experiência que eu tive com a Caixa Econômica, eu... Dessa vez, eu paguei uma pessoa que pudesse estar me ajudando... Um despachante. Pudesse estar me ajudando em algumas documentações, então... [pausa, atitude pensativa] Eu achei um pouco demorado no sentido da Caixa, porque você tem que apresentar um processo, fazer a análise todinha, o imóvel tem que estar de acordo... Eu lembro que o crédito já estava aprovado, mas é... 20 dias depois, ainda não tinha sido é..., processado, ainda (estava no) o trâmite final. E aí, essa parte aí, eu acho que teve certa demora. Não de aprovação [ênfase], mesmo porque, como eles viam que meu custo a pegar era pequeno, não teve muito a dificuldade de pegar, ser aprovada a análise. Eu estava pagando mais (referindo-se às prestações relativas ao seu primeiro empréstimo) que estava pegando naquele primeiro momento E... mas assim... achei um pouquinho demorado sim [leve expressão de desagrado]. (E1) [sic]

E6 informou que, apesar de não estar naquele momento à procura de imóvel, tinha a necessidade de tê-lo, pois já estava planejando o seu casamento; assim, quis aproveitar a oportunidade quando encontrou o apartamento que queria:

É... eu fui até a Caixa porque me interessei por um apartamento que parecia com as... com os... pré-requisitos da Minha Casa Minha Vida. E fui até a Caixa com meu marido, pra... na época era meu noivo, pra gente ver a situação do apartamento. Contratamos uma despachante pra poder facilitar o processo, até porque os dois trabalhavam, a gente não podia ficar muito tempo fora. E... assim foi feito. [expressão satisfeita] [sic]

Nos casos de E2, E4 e E7, eles informaram terem se surpreendido durante o processo da liberação do financiamento, pelo fato de terem optado em comprar o imóvel ainda a ser construído - caso em que o financiamento apresenta diferenças e maior demora do que no caso da aquisição de imóvel pronto. Os relatos apontaram, principalmente, estranheza com os fatos de o pagamento da entrada poder ser parcelado, de o negócio ser iniciado com a construtora no stand de vendas, e de essa última não se preocupar em informar claramente como se desenrola o processo da aquisição. Outra manifestação de desagrado foi colocada no que tange à espera pela conclusão da obra, considerada longa.

O depoimento de E2 ilustra esse particular, ao deixar transparecer seu aborrecimento com a consequência funesta sobre seu fluxo de caixa, da falta de clareza dos corretores, assim como da CEF. No caso, ele foi levado a entender que uma entrada de valor acima daquele que ele originalmente se propunha a dispor diminuiria o montante da dívida a ser saldada em prestações - o que, na realidade, não ocorreu:

A gente pagou a entrada e os valores começaram a mudar. É isso que eu quero ver de agora em diante, porque a gente assinou um valor (que não veio a ser respeitado) que foi passado pra gente como o valor de financiamento que a Caixa tinha aprovado. Mas recentemente fiquei sabendo que a Caixa não aprovou esse valor, aprovou um valor inferior! [ênfase, expressão de surpresa]. 0 restante da obra fica pra construtora, quer dizer, tenho que reembolsar à construtora! Então mudou tudo, (mas) eu tenho os boletos e tenho os contratos! [tom de voz se eleva]. (E2) [sic]

Situação semelhante foi experimentada por E4:

Primeiro nós fomos no stand e... Vimos tudo, fechamos tudo com os corretores. Aí, de inicial, demorou pouco tempo. Eles foram... Falaram que a gente tinha que... O valor a Caixa iria financiar e outro valor a gente tinha que pagar para a construtora, e aí a primeira parte da entrada da construtora seria parcelada, daí então a gente teria que dar R\$ 6.000 de entrada como primeira parcela... Quase $\mathrm{R} \$ 6.000$ da primeira parcela, e o resto a Caixa iria financiar. Só que, agora, depois de um tempo rolando documentação (que foi muito complicado conseguir, teve vários problemas de documentação, toda hora assinar contrato e rolar documentação, e volta tudo de novo), aí eles ligaram falando que o valor que a Caixa ia aprovar não foi aprovado! [expressão de assombro]. Aprovou menos! Então, o que é pior, o valor da entrada que você paga para a construtora aumenta! Vai aumentar! [eleva 
a voz] E aí a gente descobriu que o valor que nós pagamos que seria a primeira entrada da... a primeira parcela da entrada, virou comissão de vendedor. [expressão de desânimo]. E tivemos que pagar tudo de novo. (E4) [sic]

Por seu turno, E7 também adquiriu financiamento de imóvel em construção, mas sua reação foi de maior compreensão com as ocorrências durante o processo:

\begin{abstract}
Neste caso meu, demorou também, entendeu? Mas foi porque ocorreu lá, problemas lá na construção... Outras pessoas que compraram também receberam antes de mim, sendo que tinham comprado depois, mas comprou em outro local onde construiu tudo certinho, entendeu? [expressão serena] Conseguiu finalizar tudo rapidamente. Mas, no fim de tudo, tem aqueles problemas, mas são detalhes, entendeu?... Demorou na faixa de uns dois anos e meio para entregar, entendeu? Porque teve aí certos atrasos, mas foi na planta ... E os valores, é bom você olhar, entendeu? [em tom aconselhatório] Porque eles, muitas vezes eles alteram o valor lá, ocorre alguma coisa lá, eles pegam e embutem esse valor na sua parcela. Eu é... percebi isso, entendeu? [expressão de malícia] Entrei com uma ação na Justiça e demorou, mas consegui ser ressarcido desse valor, entendeu? Então, é muito importante que você verifique... Não só vá lá e assina, entendeu? Você tem que ler o documento, se você não ler, não reclame depois [em tom aconselhatório]. No dia que fui na Caixa Econômica para assinar os documentos, é... a garota ficou até meio assim, assustada, né? [risos] Porque normalmente o pessoal chega e assina, entendeu? E vai embora. Eu não! [ênfase] Sentei lá, demorou, mas eu li item por item entendeu? (E7) [sic]
\end{abstract}

É interessante verificar que, após esses relatos referentes às dificuldades no entendimento e no fechamento do negócio, a entrevista com E8 revelou situação totalmente oposta, indicando a total ausência de problemas processuais: "Eu ouvia falar (no programa Minha Casa Minha Vida). Entrei no site da Caixa, fiz a simulação, gostei... Tinha o dinheiro da entrada, fui lá na Caixa, conversei com o gerente e ele aceitou, e eu fiz" .[expressão tranquila] (E8) [sic]

Outra descoberta da pesquisa diz respeito à clara percepção, por parte dos entrevistados E1, E6, E7 e E8 que realizaram pesquisa prévia sobre as condições do programa governamental de financiamento da casa própria, de que ele seria preferível a outras linhas de financiamento, tais como a modalidade de consórcio. Para eles, estava muito clara a vantagem não só do menor valor a ser desembolsado a título de entrada, como também do subsídio governamental:

É, eu gostei das informações (da CEF)... Consórcio também que eu fiquei em dúvida... [expressão pensativa] Até me interessou um pouco, mas aí eu pesquisei, fiz meus cálculos meio loucos aqui. E aí me interessei, porque o governo também oferecia subsídio alto, minha renda é baixa, então ganhei o subsídio, não sei se o valor máximo... Se não me engano, foi o valor máximo. (E8) [sic]

Por outro lado, E4 demonstrou conhecimento truncado a respeito das condições do programa governamental, muito embora o veja como superior à modalidade consórcio, numa clara mistura da figura da CEF com esse tipo de iniciativa:

Não pensamos nem no consórcio. Consórcio eu acho que... la demorar muito mais, a gente nem chegou a pensar nisso. Pensamos mesmo no financiamento pela Caixa Econômica que... Meio que já é de praxe, todo mundo já vai pra lá financiar, e eu acho que o Minha Casa Minha Vida é conveniado, só pode fazer pela Caixa, acho [expressão de dúvida]. (E4) [sic]

Na pesquisa, foi identificada ingerência da tomada de crédito no orçamento familiar dos entrevistados que a priori não se informaram corretamente sobre as condições do financiamento imobiliário. Assim, conforme essa condição se consolidou em suas vidas, um novo planejamento orçamentário familiar tornou-se necessário, implicando a abdicação de novos planos e de sonhos a realizar. 
O caso de E2 é emblemático, pois, apesar de as parcelas serem compatíveis com sua capacidade de pagamento, ele não se preparara para as parcelas extras embutidas na amortização do financiamento:

A gente (ele e a noiva) tinha um planejamento para montar toda a casa, casar daqui a dois anos e ainda fazer uma cerimônia. Agora tudo isto mudou. [expressão de frustração] Eu estou sendo sincero, eu e minha noiva estamos arrependidos (de termos tomado o financiamento). Eu prefiro comprar um imóvel que não faça parte de nenhum projeto do governo, nada disso, e saber exatamente o que estou pagando, e ver com a Caixa se ela aprova ou não, do que tomar este custo agora. Porque não sei de onde vou tirar este valor... [gesto abrindo as mãos espalmadas] E agora, para reincidir o contrato, eu perco boa parte do valor da entrada. (E2) [sic]

Situação semelhante foi manifestada por E4, que também pensou em desistir do negócio, mas que se viu diante da perspectiva de perder parte do valor já empregado na entrada do financiamento. Porém, é interessante observar que, para lidar com essa situação aflitiva, ela optou por lançar mão de uma verdadeira resignificação do ato, por meio do reforço do sonho da casa própria:

\footnotetext{
Nós dois (ela e o marido) queríamos muito (uma casa própria) [sorriso]. Por isso que nós fizemos (o financiamento) mais por impulso mesmo. Acordamos, fomos lá, gostamos e fechamos negócio [expressão decidida]. Agora a gente vê esta surpresa, este problema todo (de não poder arcar com o pagamento). Mas a gente resolveu continuar (não cancelar o negócio) porque era o que a gente queria... Se não for assim, a gente não vai conseguir nunca. A gente resolveu meter a cara e continuar. (E4) [sic]
}

Durante a pesquisa, aproveitou-se a ocasião para se estender a investigação especificamente às linhas de créditos menores que são facilitadas, tais como cheque especial, cartão de crédito e crédito pessoal.

No caso, o que se verificou é que os entrevistados têm bastante conhecimento a respeito, mas seus comportamentos sobre como tomá-los seguiu um padrão muito claro de aversão ao comprometimento com o pagamento de juros:

\begin{abstract}
Ah, sim! (referindo-se a conhecer estes recursos). Não, não, tenho (o hábito de usá-los). Eu sou uma pessoa bem controlada em relação a isso; não gosto. Tenho até meus limites, mas dificilmente eu entro, tenho uma preocupação muito grande, evito... Até porque tenho filho, né? [sorriso, sobrancelhas levantadas] (E1) [sic]
\end{abstract}

(Peguei crédito para reforma da casa pelo Construcard porque) cartão de crédito gera um custo maior e as lojas cobram bem mais... Este (o Construcard) sai como à vista, você ganha até desconto. (E3) [sic]

(Não uso cheque especial) porque a taxa de juros é alta e eu não gosto. (E5) [sic]

Tenho, tenho cartão de crédito, cheque especial. Só utilizo cartão de crédito, porque o cheque especial te cobra juros de qualquer maneira. (E6) [sic]

(O banco) até ofereceu (linha de crédito), mas eu não quis não, para não pagar juros... Eu não quis não [balança a cabeça negativamente]. Odeio. [ênfase no verbo] (E8) [sic]

Uma segunda constatação paralela na pesquisa diz respeito ao desejo dos entrevistados de guardarem uma reserva financeira para eventuais necessidades emergenciais - muito embora isso, muitas vezes, se torne impossível quando a renda passa a ser comprometida quando um financiamento é assumido: 
A gente (ele e a noiva) sempre teve esse costume (de guardar uma reserva), até porque a gente fez um planejamento (do orçamento do casal) dentro do que foi passado pra gente (quando tomaram o financiamento), de o que a gente queria comprar. A gente fez todo um planejamento, de quanto a gente poderia gastar, de quanto a gente poderia pagar... Tudo foi dividido meio a meio (entre ele e a noiva) certinho. Agora, com essa mudança... [expressão de desânimo] (E2) [sic]

É... hoje a gente... meio que mudou o nosso modo de viver, passamos a gastar menos com coisas inúteis [risos], e... pra poder juntar (dinheiro). Porque a gente tá pensando mais pra frente, questão de mobiliar a casa, essas coisas... Então a gente separa o valor que já tem que pagar das parcelas... Ainda mais agora, que deu esse problema com o financiamento (despesas inesperadas)... Tentamos separar um valor, mesmo que não seja muito, para deixar pra mobiliar a casa que tá no papel, outra pra qualquer eventualidade que aconteça, pra ter um valor guardado. (E4) [sic]

Sempre tive o hábito de guardar dinheiro. Agora um pouco menos, mas... (ar de riso). Eu consigo, mas não... perto do que eu juntava. (E6) [sic]

Consigo sim (juntar dinheiro). Eu tinha o costume, a partir do momento que eu adquiri minha auto-suficiência. Percebi a importância de você cuidar bem do seu dinheiro, porque dinheiro é algo essencial pra gente ter o que a gente quer, né? [sobrancelhas levantadas] (E7) [sic]

Da forma que eu guardava antes, não mais (consigo economizar), como disse, porque eu guardava mais porque não tinha essa prestação (do financiamento)... Mas hoje ainda é possível guardar um pouco de dinheiro, bem pouco, mas... Guardar dinheiro sempre tem que guardar, né? (sorriso) Sempre gostei de guardar, nem que seja o mínimo possível, pelo menos $10 \%$ (do que ganho), nem que eu corte viagem, roupa, diminua as coisas que eu acho supérfluas... Tem que guardar porque a gente não sabe o dia de amanhã. (E8) [sic]

Por outro lado, a própria prestação do financiamento pode ser encarada como substituta da poupança que não se pode mais fazer, dando à pessoa a sensação de "ainda estar economizando":

Infelizmente, assim (com o financiamento assumido) não dá (para economizar)! o que eu coloquei na minha prestação era o que eu guardava. Então a minha prestação não ficou diferente de uma coisa que eu já estava fazendo para comprar o imóvel... Hoje é certinho aquele valor ali, todos os meses. (E1) [sic]

\section{CONCLUSÃo}

O que se verificou foi que a visão desses representantes das classes $C$ e $D / E$, quanto às condições processuais da tomada das linhas de crédito e de financiamentos incentivados pelo Governo Federal, pode variar. No caso, pode ser interpretado como um processo complexo, com várias etapas, e com obstáculos, por vezes, desestimulantes ao cliente - o que explica por que alguns dos usuários optem por evitá-los, contratando profissional despachante para cuidar dos trâmites - até um evento não só simples como rápido.

No caso, a diferença entre esses desempenhos pareceu estar muito mais ligada aos próprios perfis dos usuários do que a qualquer outro motivo. Assim, pessoas que têm o hábito de pesquisar antecipadamente sobre as condições, ou que costumam analisar os documentos em detalhes antes de os assinar, revelaram não terem tido surpresas ao longo dos processos. 
Por outro lado, os casos de reclamações provieram daqueles que, por força de características pessoais, ou por simples falta de prática nesse tipo de negócios, se viram surpreendidos por desdobramentos que os aborreceram.

Já no que tange à investigação quanto aos reflexos que essa tomada possa ter sobre a organização financeira dessas pessoas, o que se observou foi que, de uma forma geral, os sujeitos pesquisados souberam administrar a nova situação, sem que essa tomada de crédito impactasse negativamente suas finanças pessoais. Obviamente houve casos em que foi ressaltada a necessidade de o usuário ter sido obrigado a reestruturar alguns hábitos antigos de consumo, mas dentro daquilo que se poderia entender como um procedimento razoável e normal, principalmente levando-se em conta que a disponibilidade de renda dessas classes econômicas analisadas é limitada. Nesse particular, chamou a atenção o caso de um entrevistado que passou a enxergar seu compromisso com o financiamento tomado como uma forma de poupança, o que não deixa de ter certa lógica, tendo em vista a limitação de recursos de que esse público dispõe.

Vale notar, ainda, que alguns fatos percebidos durante a pesquisa de campo - e que não foram aqui explorados por não pertencerem aos objetivos primários da investigação - colocam-se como interessantes propostas para futuros estudos.

O primeiro remete ao fato de a relação entre os tomadores do financiamento e a CEF ter sido eventualmente mediada por agentes do mercado financeiro, sugerindo investigação sobre até que ponto esse último pode ter pesado na maior ou menor satisfação dos usuários.

O segundo seria a dificuldade que os tomadores de empréstimos não raro apresentam na identificação correta dos agentes envolvidos no processo, tais como governo, CEF e construtoras. No caso, investigar até que ponto essa falta de esclarecimento contamina a percepção de satisfação dos tomadores de empréstimos também poderia trazer insights interessantes ao assunto.

O terceiro teria a ver com a gestão orçamentária do público aqui pesquisado. Isso porque a pesquisa primária identificou que sua capacidade de poupança e sua gestão do crédito podem variar em função de aspectos cotidianos ou excepcionais de suas vidas, havendo uma maior facilidade nesse esforço quando se trata das modalidades cotidianas e de consumo mais imediato, tais como cheque especial e cartão de crédito. Assim, valeria a pena investigar se a maior dificuldade encontrada no caso do financiamento habitacional teria a ver com o fato de se tratar de algo excepcional, não recorrente, ligado mais à questão patrimonial-familiar que ao consumo individual.

Essa dúvida poderá ser sanada em futuros estudos, os quais também poderão utilizar abordagem quantitativa, na qual a investigação junto a uma amostra significativa poderá trazer resultados generalizáveis. 


\section{REFERÊNCIAS}

ABEP - Associação Brasileira de Empresas de Pesquisa. Disponível em < http://www.abep.org/novo/ Content.aspx?Content|D=835>. Acesso em 25 set. 2013.

BALDOCHI, G. IPI reduzido diminui estoques nas concessionárias em junho. Folha de São Paulo, São Paulo. Disponível em http://www1.folha.uol.com.br/folha/dinheiro/ult91u93588.shtml> Acesso em 03 jul.2012.

CHEQUE ESPECIAL. Disponível em <http://www.caixa.gov.br/Voce/Credito/Credito_Pessoal/cheque_ especial/index.asp>. Acesso em 16 abr. 2014.

COOPER, D.; SCHINDLER, P. Métodos de pesquisa em administração. Porto Alegre: Bookman, 10ª ed., 2011.

CRÉDITO DIRETO AO CONSUMIDOR. Disponível em <http://www.brasil.gov.br/economia-eemprego/2009/11/credito-direto-ao-consumidor-cdc>. Acesso em 16 abr. 2014.

CRÉDITO IMOBILIÁRIO. Disponível em <http://www.hsbc.com.br/1/2/creditoimobiliario >. Acesso em 16 abr. 2014.

CRÉDITO PESSOAL. Disponível em <http://www.caixa.gov.br/Voce/credito/credito_pessoal/index.asp>. Acesso em 16 abr. 2014.

DAMASCENA, E.; FARIAS, S. Os elementos sensoriais em supermercados: um estudo junto a pessoas com deficiência visual na perspectiva da pesquisa transformativa do consumidor. XXXVII Encontro da ANPAD. Anais. Rio de Janeiro (RJ), setembro 2013.

EMPRÉSTIMO CONSIGNADO. Disponível em <http://www.caixa.gov.br/voce/Credito/emprestimo aposentados/emprestimo_consignado/index.asp>. Acesso em 16 abr. 2014.

ESTADÃO. Inadimplência do consumidor recua 5,5\% em agosto, diz Serasa. 11 setembro 2013. Disponível em $<$ http://economia.estadao.com.br/noticias/economia,inadimplencia-do-consumidor-recua- 55 -emagosto-diz-serasa, 164380,0.htm>. Acesso em 25 set. 2013.

FELIX, J. Pesquisa: IPI reduzido amplia viagens de carro na classe C. Poder Econômico. 08 out 2012. Disponível em http://colunistas.ig.com.br/poder-economico/2012/10/08/pesquisa-ipi-reduzidoamplia-viagens-de-carro-na-classe-c/. Acesso em 17 set. 2013.

FOLHA DE SÃO PAULO. Classe E impulsiona mercado de cartões de crédito, revela Serasa. 04 setembro 2013. Disponível em <http://www1.folha.uol.com.br/mercado/2013/09/1337003-classe-e-impulsionamercado-de-cartoes-de-credito-revela-serasa.shtml>. Acesso em 25 set. 2013.

FOLHA ONLINE. Programa de inclusão bancária já conta com 3,8 milhões de correntistas. 19 fevereiro 2005. Disponível em <http://www1.folha.uol.com.br/folha/dinheiro/ult91u93588.shtml >. Acesso em 25 set. 2013.

G1. Consumo no Brasil deve crescer 10\% em 2013, para R\$ 1,55 tri, diz lbope. 04 set 2013. Disponível em <http://g1.globo.com/economia/noticia/2013/09/consumo-no-brasil-deve-crescer-10-em-2013para-r-155-tri-diz-ibope.html>. Acesso em 25 set. 2013. 
GILL, R. Análise de discurso. In: BAUER, M. W.; GASKELL, G. Pesquisa qualitativa com texto, imagem e som. Petrópolis: Vozes, 2002.

MICROCRÉDITO CAIXA. Disponível em <http://www.caixa.gov.br/voce/credito/geracao_emprego_renda/ cred_microcred/index.asp>. Acessoem 16 abr. 2014.

MINHA CASA, MINHA VIDA. Disponível em <http://www.caixa.gov.br/habitacao/mcmv/>. Acesso em 16 abr. 2014.

MORCILLO, F. M. (2007, p. 134). Princípios de economia. São Paulo: Pearson Prentice Hall.

PAC - Programa de Aceleração do Crescimento. Disponível em < www.pac.gov.br >. Acesso em 01 dez. 2013.

PORTAL BRASIL. Prorrogada redução de IPI para linha branca. 26 mar 2012. Disponível em <http:// www.brasil.gov.br/economia-e-emprego/2012/03/prorrogada-reducao-de-ipi-para-linha-branca>. Acesso em 29 set. 2013.

PROGRAMA NACIONAL DE HABITAÇÃO RURAL. Disponível em <http://www1.caixa.gov.br/gov/gov_social/ municipal/assistencia_tecnica/produtos/repasses/pnhr_ogu/index.asp> Acesso em 16 abr. 2014.

PROGRAMA CRÉDITO SOLIDÁRIO. Disponível em <http://www.caixa.gov.br/habitacao/operacoes_ coletivas/programa_credito_solidario/index.asp> Acesso em 16 abr. 2014.

QUEIROZ, S.; REMY, M.; PEREIRA, J.; SILVA FILHO, L. Análise da evolução dos programas federais de transferência de renda (PBF e BPC) no Brasil e estados do Nordeste - 2004-2009. XVII Encontro Nacional de Estudos Populacionais (ABEP). Anais. Setembro, Caxambu (MG), 2010.

SEBRAE - Serviço Brasileiro de Apoio às Micro e Pequenas Empresas. Disponível em < http://www.sebrae. com.br/uf/rondonia/orientacao-empresarial/credito-e-microcredito/caracteristicas-do-microcredito/ BIA_452>. Acesso em 17 set. 2013.

THOMAZ, P. Classe C já tem 52\% da população. Carta Capital, 08 agosto 2011. Disponível em <http:// tebloga.wordpress.com/2011/08/08/inclusao-mais-da-metade-da-populacao-brasileira-ja-faz-parteda-classe-c/>. Acesso em 01 dez. 2013.

VILLAVERDE, J. Governo dá novo estímulo ao consumo. 13 junho 2013. Disponível em <http://csbbrasil. org.br/governo-da-novo-estimulo-ao-consumo/>. Acesso em 26 set. 2013.

VERGARA, S. C. Projetos e relatórios de pesquisa em administração. São Paulo: Atlas, 2013.

WILHER, V. Perspectivas para a economia brasileira e condução da política monetária no segundo semestre de 2013. 26 julho 2013. Disponível em <http://www.conjuntura.uff.br/resenhas-de-conjuntura/ perspectivas-para-a-economia-brasileira-e-conducao-da-politica-monetaria-no-segundo-semestrede-2013/>. Acesso em 25 set. 2013. 